\title{
The Teaching of Subjects Related to Pharmacovigilance in Malaysian Pharmacy Undergraduate Programs
}

Ramadan M. Elkalmi ${ }^{1 *}$, Mohamed Azmi Ahmad Hassali ${ }^{2}$, Omer Qutaiba B. Al-lela ${ }^{1}$ and Shazia Q. Jamshed ${ }^{1}$

${ }^{1}$ Department of Pharmacy Practice, Kulliyyah of Pharmacy, International Islamic University, Malaysia

${ }^{2}$ Discipline of Social and Administrative Pharmacy, School of Pharmaceutical Sciences, University Sains, Malaysia

\begin{abstract}
Objectives: To evaluate the extent to which subjects related to pharmacovigilance are taught in the pharmacy programs within Malaysian universities.

Methods: Self-completed questionnaires were sent (via surface mail) to all heads of schools and faculties of pharmacy and medicine that offer pharmacy programs in Malaysia. The questionnaires were intended for department heads or the person responsible for the teaching of the subject in the respective institutions.

Results: Thirteen out of fourteen ( $n=13,92.8 \%)$ medical and pharmacy schools responded to the survey. The vast majority $(n=11, N=13,84.6 \%)$ of the pharmacy programs within the studied Malaysian universities feature pharmacovigilance-related topics in their undergraduate syllabi. About two-thirds $(n=8,72.7 \%)$ of the pharmacy programs taught issues related to pharmacovigilance within epidemiology and/or pharmacoepidemiology courses. Pharmacovigilance-related topics are core/required in almost all $(n=9,81.8 \%)$ of the pharmacy programs. None of the pharmacy programs had a specific stand-alone course on pharmacovigilance.

Conclusion: Subjects related to pharmacovigilance were widely taught in the majority of the universities surveyed. As the field of pharmacovigilance is very important for future pharmacy practitioners, this course should be made a core course within the local pharmacy curriculum in order to enhance medication safety for the population. To ensure effective practice in the area of drug safety, there is an urgent and necessary need for Malaysian pharmacy students to be adequately educated and exposed to the contemporary issues and challenges of pharmacovigilance implementation.
\end{abstract}

Keywords: Pharmacovigilance; Undergraduate education; Malaysia; Curricula; Pharmacy program

\section{Introduction}

The spontaneous Adverse Drug Reaction (ADR) reporting system is considered the most important method of collecting and monitoring information pertaining to drug-related safety issues. Described as the simplest and most cost-effective method of ADR reporting, spontaneous reporting is a major source of information within pharmacovigilance [1-3]. The Malaysian pharmacovigilance system administrated by the Malaysian Drug Control Authority (DCA), through the Malaysian Adverse Drug Reaction Advisory Committee (MADRAC), has been in operation for more than twenty-five years.

The number of ADR reports received by MADRAC reached 5760 in 2010 [4], which is within the WHO recommendation for an optimal pharmacovigilance system. Since its establishment, MADRAC has invited healthcare professionals (physicians, pharmacists, dentists, etc.) to submit reports; in 2008, consumers were invited to report as well. However, no study has been conducted to explore the extent of underreporting within the Malaysian context. The literature indicates that the Malaysian pharmacovigilance system suffers from underreporting, as do many other pharmacovigilance systems around the globe.

While community pharmacists in Malaysia appear supportive of and show positive attitudes towards ADR reporting, many barriers hinder their involvement in pharmacovigilance activities. Elkalmi et al., reported that ignorance of where the report should be sent and the unavailability of reporting forms were the most common obstacles leading to non-reporting among Malaysian community pharmacists [5]. With regard to other healthcare professionals, Zoriah et al., reported that about $40 \%(n=350)$ of physicians were unaware of the existence of the reporting system in the country [6]. Insufficient promotion and weak communication between pharmacists and the relevant authorities has been reported as barriers to ADR reporting. It has been suggested that education on pharmacovigilance and ADR reporting should be included within medical training [7]. Mariani et al., noted the importance of considering pharmacovigilance an essential part of the academic training of medical and scientific operators; furthermore, she concluded that pharmacovigilance is a field where universities and professional societies may play quite a significant role [8].

The role of pharmacists in drug safety issues is well recognized: they possess the medical knowledge to understand adverse drug events and medication errors, and are expected to have the prerequisite technical knowledge to report adverse events [9]. The unique position of pharmacists as the front line for patient information regarding drug use, as well as information about ADRs, means it is important that they learn about the pharmacovigilance concept and are equipped with the necessary skill to report ADRs. A survey study among 421 pharmacy students (from 5 Malaysian public universities) that explored their

*Corresponding author: Dr. Ramadan M. Elkalmi, Department of Pharmacy Practice, Kulliyyah of Pharmacy, International Islamic University, 25200 Kuantan, Pahang, Malaysia, Tel: +609 5716400 Ext 3201; Fax: +609 571 6775; E-mail: edriph@gmail.com

Received January 14, 2013; Accepted January 26, 2013; Published January 28, 2013

Citation: Elkalmi RM, Ahmad Hassali MA, Al-lela QBO, Jamshed SQ (2013) The Teaching of Subjects Related to Pharmacovigilance in Malaysian Pharmacy Undergraduate Programs. J Pharmacovigilance 1: 106. doi:10.4172/2329-6887.1000106

Copyright: (c) 2013 Elkalmi RM, et al. This is an open-access article distributed under the terms of the Creative Commons Attribution License, which permits unrestricted use, distribution, and reproduction in any medium, provided the original author and source are credited. 
Citation: Elkalmi RM, Ahmad Hassali MA, Al-lela QBO, Jamshed SQ (2013) The Teaching of Subjects Related to Pharmacovigilance in Malaysian Pharmacy Undergraduate Programs. J Pharmacovigilance 1: 106. doi:10.4172/2329-6887.1000106

Page 2 of 5

knowledge and perceptions of pharmacovigilance demonstrated that the vast majority of the surveyed students (87\%) agreed that there is a need to educate and provide pharmacy students with necessary information on pharmacovigilance and how to report ADRs [10]. In addition, the involvement of pharmacy students in pharmacovigilance activities contributed significantly to increasing the number of documented ADRs [11]. It has been reported that continuous education and training on pharmacovigilance for healthcare professionals has a major impact on their attitude and perception towards ADR reporting, as well as improving ADR reporting [12]. Education and training was the most recognized means of improving ADR reporting [6,13-15]. However, the current educational and training programs on ADR reporting and pharmacovigilance activities provided to the pharmacy students has been found to be inadequate [16]. There is an opportunity to increase the involvement of the drug control authorities and an urgent need to integrate education/training on pharmacovigilance and ADR reporting within undergraduate medical and pharmacy education [10,16,17]. In Malaysia, in the mid-nineties only one governmental university offer pharmacy program, during the study period (from December 2010 to February 2011) there were 14 universities and colleges provide pharmacy programs within pharmacy and medical schools. Most of these pharmacy programs require four years of full-time study for the B Pharm pharmacy degree.

Over the last 20 years, there was a landmark transformation in the orientation of the pharmaceutical education, in 70s the pharmacy curriculum focus mainly on pharmaceutical chemistry and dispensing. Currently about $20 \%$ of the pharmacy curriculum devoted for clinical and about $10 \%$ intended for social and management pharmacy $[18,19]$. It is worth to mention here that clinical and basic sciences are taught as integrated papers. Entrance of pharmacy profession required successful complete of 4-years bachelor of sciences (B.Sc.) degree followed by the completing compulsory twelve months of pre-registration training in an establishment recognized by the Malaysian pharmacy board. This study was carried out to explore the extent of teaching about the pharmacovigilance concept and ADR reporting in pharmacy programs within Malaysian schools of pharmacy and medicine.

\section{Methods}

A new, validated, self-completed and prepaid questionnaire consisting of thirty-two closed-ended questions and one open question was developed.

\section{Questionnaire development and validation}

Questionnaire items were developed from a thorough review of variables and factors used in previous studies and previous survey instruments used to assess pharmacoepidemiology and pharmacoeconomic education being though in US pharmacy programs $[3,16,20-24]$. The final questionnaire comprised of 5 sections. The first section (I) of the questionnaire collected demographics data and other information pertaining the previous training and experience of the respondents in the field of pharmacovigilance. Section (II) contained questions on current status of teaching pharmacovigilance in the pharmacy programs, involvement of the respondents in the teaching process, on the courses in which the pharmacovigilance-related topic(s)/content(s) being taught, category status of the of the course(s) and finally, the pharmacovigilance-related content areas (topics) that are currently included in the curriculum and in what year the pharmacovigilance-related content featured. Section (III) contained 10 items aimed to determine the methods of delivery of pharmacological vigilance related topics. The last section (IV) was to assess the respondents' views on importance of pharmacovigilance teaching to the academic and pharmacy students. They were requested to describe the level of agreement/disagreement on the pharmacovigilance teaching using a 4-point Likert scale anchored at not important and very important $[1,4]$.

The questionnaire was tested on its face and content validity by three experts involved in the teaching of pharmacovigilance in the School of Pharmaceutical Sciences, Universiti Sains Malaysia (USM). Suggestions from these experts were incorporated into a final draft. The final questionnaire was mailed to all the heads of pharmacy and medical schools offering pharmacy programs in Malaysia $(n=14)$. One postal reminder was sent to non-respondents four weeks after the dispatch of the survey questionnaire. The data were analyzed descriptively using Statistical Package for the Social Sciences, version 20.0, (SPSS Inc., Chicago, IL, USA). No inferential statistical tests were conducted.

\section{Results}

A total of thirteen (92.8\%) pharmacy/medical schools, out of fourteen universities offering pharmacy programs during the study period, responded. Two questionnaires were excluded from the analysis: one questionnaire was returned blank and another school did not teach pharmacovigilance within their pharmacy program. The total number of usable questionnaires was thus eleven (78.5\%).

Responding on behalf of the pharmacy /medical schools were deans $(n=4,36.4 \%)$, a program chairman $(n=1,9.0 \%)$, program coordinators $(n=4,36.4 \%)$ and department heads $(n=2,18.2 \%)$. About sixty percent $(63.6 \%)$ of the respondents were male and the majority were between 30 and 39 years of age. More than three- quarters $(n=9$, $81.8 \%$ ) of the respondents held either a Doctor of Philosophy (PhD) or Doctor of Pharmacy (Pharm D) degree while less than twenty percent $(n=2,18.2 \%)$ indicated that they held either M. Pharm or M.Sc. degrees (Table 1).

\begin{tabular}{|c|c|c|}
\hline Details & Frequency & Percentage (\%) \\
\hline \multicolumn{3}{|l|}{ Gender } \\
\hline Male & 7 & (63.6) \\
\hline Female & 4 & $(36.4)$ \\
\hline \multicolumn{3}{|l|}{ Age } \\
\hline $30-39$ & 6 & $(54.5)$ \\
\hline $40-49$ & 2 & $(18.2)$ \\
\hline $50-59$ & 2 & (18.2) \\
\hline$>60$ & 1 & $(9.1)$ \\
\hline \multicolumn{3}{|l|}{$\begin{array}{l}\text { Type of position hold } \\
\text { in the school/faculty }\end{array}$} \\
\hline Dean & 4 & $(36.4)$ \\
\hline Program chairman & 1 & $(9.1)$ \\
\hline Program coordinator & 4 & $(36.4)$ \\
\hline Department head & 2 & $(18.2)$ \\
\hline \multicolumn{3}{|l|}{ Academic qualification } \\
\hline MPharm/MSc. & 2 & $(18.2)$ \\
\hline PharmD/PhD & 9 & $(81.8)$ \\
\hline \multicolumn{3}{|l|}{ JOP TITLE } \\
\hline Lecturer & 6 & $(54.5)$ \\
\hline Assoc. Prof & 3 & $(27.3)$ \\
\hline Professor & 2 & $(18.2)$ \\
\hline
\end{tabular}

Table 1: Socio-demographic details of the respondents $(n=11)$. 
Citation: Elkalmi RM, Ahmad Hassali MA, Al-lela QBO, Jamshed SQ (2013) The Teaching of Subjects Related to Pharmacovigilance in Malaysian Pharmacy Undergraduate Programs. J Pharmacovigilance 1: 106. doi:10.4172/2329-6887.1000106

Page 3 of 5

The majority of the respondents $(n=8,72.7 \%)$ stated they were currently involved in the teaching of pharmacovigilance and had learned about pharmacovigilance during their study time. Only four (36.4\%) of the respondents had previously received formal training on pharmacovigilance. Almost all $(\mathrm{n}=10,90.9 \%)$ of the respondents indicated that their school/faculty included pharmacovigilance-related topics in its Bachelor of Pharmacy (B. Pharm) curriculum (Table 2).

\section{Status of pharmacovigilance teaching in Malaysian pharmacy programs}

The study results indicated that pharmacovigilance and related topics were taught as part of a B. Pharm curriculum in the all of the studied pharmacy programs $(\mathrm{n}=11,100 \%)$, Pharmacovigilance and related topics were taught during the fourth (final) year in nine schools $(n=9,81.8 \%)$ and during the second and fourth years in one school.

The study results indicated that the teaching of pharmacovigilancerelated topics was normally integrated into pharmacoepidemiology and clinical pharmacy courses and incorporated into other courses as well (Table 3). The number of hours allocated specifically for teaching pharmacovigilance in these courses was three hours and less in two pharmacy programs $(\mathrm{n}=2,18.1 \%)$ and four to six hours in seven programs $(n=7,63.6 \%)$. Only a few $(n=2,18.1 \%)$ respondents indicated that six hours and more had been devoted to the teaching of pharmacovigilance-related topics in their pharmacy programs (Figure 1). The study findings revealed that the courses in which pharmacovigilance and related topics were incorporated were taught as core (required) courses in nine pharmacy programs $(n=9,81.8 \%)$ and as elective courses in the remaining two programs $(n=2,18.1 \%)$.

\section{Pharmacovigilance course material content description}

Malaysian pharmacy programs varied in the content of their teaching about pharmacovigilance. The vast majority $(n=9,81.1 \%)$ of the respondents described the most common pharmacovigilance and related topics that were included in their program's curriculum were epidemiology of adverse drug reactions, terminology of pharmacovigilance issue related to ADR reporting form and reporting process and the role of pharmacists in pharmacovigilance and ADR reporting. The clinical aspects of $\mathrm{ADR}$ and importance of $\mathrm{ADR}$

\begin{tabular}{|l|l|l|}
\hline \multicolumn{1}{|c|}{ Detail } & Frequency (n) & Percent (\%) \\
\hline $\begin{array}{l}\text { Have you ever learnt about pharmacovigilance- } \\
\text { related topics in curriculum during your study } \\
\text { period? }\end{array}$ & & \\
\hline Yes & 8 & $(72.7)$ \\
\hline No & 2 & $(27.3)$ \\
\hline $\begin{array}{l}\text { Have you had any previous formal training on } \\
\text { pharmacovigilance -related issues? }\end{array}$ & & \\
\hline Yes & 7 & $(63.6)$ \\
\hline No & 4 & $(36.4)$ \\
\hline $\begin{array}{l}\text { Does your school include pharmacovigilance } \\
\text {-related topics in its B.Pharm curriculum? }\end{array}$ & 10 & \\
\hline Yes & 1 & $(90.9)$ \\
\hline No & & $(9.1)$ \\
\hline $\begin{array}{l}\text { Do you (as a person) currently teach any of the } \\
\text { pharmacovigilance -related topic(s)/course(s) in } \\
\text { your school? }\end{array}$ & & \\
\hline Yes & 8 & $(72.7)$ \\
\hline No & 3 & $(27.3)$ \\
\hline
\end{tabular}

Table 2: Current and previous experience of the respondents related to pharmacovigilance activities. reporting have been taught in the all of the pharmacy programs $(n=11$, 100\%). The responses are presented in table 4.

\section{Teaching style and methods of pharmacovigilance course delivery}

The respondents were asked about the teaching style and methods of delivery used in teaching pharmacovigilance and related topics to pharmacy students in their pharmacy programs. The results of this study showed that didactic lecture $(\mathrm{n}=11,100 \%)$ and supplying students with instructors' handouts $(\mathrm{n}=10,90.9 \%)$ were the most common teaching tactics used for topics related to pharmacovigilance in the pharmacy programs examined. Hands-on training in ADR reporting has been adopted by only three $(n=3,72.2 \%)$ pharmacy programs. None of the examined pharmacy programs used role-playing techniques in the teaching of pharmacovigilance. These responses are summarized in table 5 .

\section{How many hours are allocated for teaching the pharmacovigilance -related contents in the course(s)?}

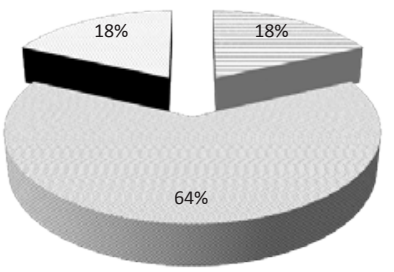

Figure 1: Details of hours allocated for teaching pharmacovigilance subjects related contents in the courses.

\begin{tabular}{|c|c|}
\hline Courses & Number of Schools \\
\hline Pharmacoepidemiology & 8 \\
\hline Clinical Pharmacy & 3 \\
\hline Therapeutics & 1 \\
\hline Pharmacology & 1 \\
\hline Other courses & 4 \\
\hline
\end{tabular}

* In some schools, it is integrated with more than one course.

Table 3: Courses that include Pharmacovigilance and Related topics in Pharmacy Programs*.

\begin{tabular}{|l|l|c|}
\hline No. & \multicolumn{1}{|c|}{ Topics covered } & $\begin{array}{c}\text { Number of } \\
\text { Schools(n) }\end{array}$ \\
\hline 1 & Clinical Aspects of ADRs & 11 \\
\hline 2 & Importance of ADR Reporting & 11 \\
\hline 3 & Malaysian National Pharmacovigilance System & 10 \\
\hline 4 & Epidemiology Of Adverse Drug Reactions (ADRs) & 9 \\
\hline 5 & $\begin{array}{l}\text { Issues related to ADR reporting forms and reporting } \\
\text { process }\end{array}$ & 9 \\
\hline 6 & $\begin{array}{l}\text { Role of Pharmacist in Pharmacovigilance and ADR } \\
\text { reporting }\end{array}$ & 9 \\
\hline 7 & $\begin{array}{l}\text { Terminology in Pharmacovigilance } \\
\text { Involvement of Pharmacist in Pharmacovigilance } \\
\text { activities }\end{array}$ & 8 \\
\hline 8 & $\begin{array}{l}\text { Different approaches to stimulate ADR reporting like } \\
\text { interviews, telephone calls, counseling and group } \\
\text { discussion. }\end{array}$ & 7 \\
\hline 9 & Others & 1 \\
\hline 10 & & 8 \\
\hline
\end{tabular}

Table 4: Type and content of Pharmacovigilance Related topics included in Pharmacy curriculum*. 


\section{Respondent opinions about teaching pharmacovigilance in pharmacy schools}

In this survey, the respondents were asked - as they are academic leaders and potentially involved in the teaching of pharmacovigilancerelated topics - for their opinions on the amount of pharmacovigilance and related topics taught in the Malaysian pharmacy programs, and for their views regarding the importance of teaching pharmacovigilance to pharmacy students as well as to other pharmacists working in different practice settings.

Nearly all of the respondents $(n=10,90.9 \%)$ believed that the amount of pharmacovigilance and related topics taught in their current B. Pharm curriculum was adequate. Only one $(n=1,9.0 \%)$ of the respondents was unsure of the adequacy of the material provided that featured pharmacovigilance-related topics. In response to a question regarding the importance of including pharmacovigilance and related topics in pharmacy curricula, ten $(n=10,90.9 \%)$ respondents considered it very important or important while only one $(n=1,9.0 \%)$ respondent felt it was somewhat important.

In addition, respondents were asked to rate the importance of pharmacovigilance to pharmacists in other academic and practice settings. All respondents considered competence in pharmacovigilance and ADR reporting to be imperative for pharmacists regardless of their practice settings (academia, community or hospital settings) (Table 6).

\section{Discussion}

The role of pharmacists has expanded from the traditional function of dispensing medications to being an integral part of the healthcare team, with an expertise in patient therapy management [25]. In response to the remarkable and rising demand for pharmacists who are competent and knowledgeable in patent-drug safety, there is a critical need for future pharmacy practitioners to understand and sensitize the broader concept of pharmacovigilance, which mainly focuses on improving patient health in either community or hospital settings. Several studies that explored pharmacists' attitudes and perceptions regarding their role in pharmacovigilance have indicated that they were highly appreciated and have positive attitudes regarding pharmacovigilance activities, but needed additional training and education programs to extend their role in the field $[10,16,22]$. In most developed countries, pharmacy schools have integrated pharmacovigilance courses as one of the core subjects to be taught in undergraduate curricula [20]. The major challenge for Malaysian pharmacists is acquiring knowledge about the pharmacovigilance concept and the capability to reliably incorporate it into their routine patient care. It has been reported that the principal challenge for the implementation of pharmacovigilance is translating the results of findings in an effective and timely manner into patient pharmaceutical care and effective communication with the public [26].

In Malaysia, pharmacists are recognized as part of the public health workforce [27], and MADRAC has recognized pharmacists as ADR reporters since its establishment in 1987 [4,27]. To enable pharmacists to practice effectively in the field of pharmacovigilance, there is a corresponding need for pharmacy students (i.e., future pharmacy practitioners) to be adequately trained and exposed to the current problems and challenges of practicing and implementing pharmacovigilance. In addition, pharmacy students should be able to integrate and apply the concepts of pharmacovigilance gained from their didactic courses into their daily practice in the community. Several

\begin{tabular}{|l|c|}
\hline \multicolumn{1}{|c|}{ Variable } & $\begin{array}{c}\text { Number of } \\
\text { Schools }\end{array}$ \\
\hline Didactic lectures & 11 \\
\hline Use of case presentations & 10 \\
\hline Provide students with instructors' handout & 9 \\
\hline Assignments to read from textbooks & 9 \\
\hline Assignments to read journal articles & 9 \\
\hline Small group discussions & 8 \\
\hline Written homework assignments & 6 \\
\hline Use of online materials & 6 \\
\hline Hands on training in ADR reporting & 3 \\
\hline Use of role-plays & 0 \\
\hline
\end{tabular}

*In same of pharmacy programs multiple methods were cited.

Table 5: Teaching style and methods of delivery of pharmacovigilance related topics used in pharmacy programs*.

studies have been conducted among healthcare professionals worldwide aimed at further uncovering the issues related to ADR underreporting and suggesting possible measurers to overcome the problem $[5,22,28$ 30]. These studies have demonstrated the vital impact of education and training in pharmacovigilance on rates of detection and quality of ADR reporting [9]. Furthermore, researchers have shown that the patient safety knowledge of medical trainees is limited [31], and that a lack of basic knowledge about ADRs and pharmacovigilance activities has been associated with ADR underreporting [32]. Christensen et al. concluded that adequate training of pharmacists on pharmacovigilance during their community pharmacy internships can significantly improve the detection and reporting of ADR by trainee pharmacists [33].

To the best of our knowledge, this is the first study that has evaluated the extent and level of the pharmacovigilance teaching provided to pharmacy students in undergraduate pharmacy programs in Malaysia. During the study period there were fifteen universities and colleges that provided approved pharmacy programs within pharmacy and medical schools.

Although this survey had a high response rate and gave a preliminary idea of the current status of teaching pharmacovigilance in pharmacy programs in Malaysia, it had some limitations. This study did not explore the assessment methods adopted to evaluate the teaching of pharmacovigilance and related topics in the pharmacy programs examined. Nevertheless, this study shed light on much information that can be used during the construction or amending of the curricula pertaining to the teaching of pharmacovigilance and related topics within undergraduate pharmacy programs. Finally, no definition of pharmacovigilance content was provided to the respondents. It is possible that the respondents had different and erroneous understanding of what covering pharmacovigilance content is and involves.

\section{Conclusion}

Future pharmacy practitioners should have basic knowledge regarding pharmacovigilance and should be equipped with the necessary skills to perform ADR reporting. Future pharmacists should have the competence to detect and monitor ADRs and should be familiar with their national pharmacovigilance system. National and official guidelines regarding pharmaceutical-related topics should be formulated as soon as possible in co-operation with other stakeholders involved in pharmacovigilance activities. Guidelines for the number of hours required to provide training on the basic aspects of pharmacovigilance, as well as more rigorous and precise planning of what topics should be included, appear to be vital and necessary. 
Citation: Elkalmi RM, Ahmad Hassali MA, Al-lela QBO, Jamshed SQ (2013) The Teaching of Subjects Related to Pharmacovigilance in Malaysian Pharmacy Undergraduate Programs. J Pharmacovigilance 1: 106. doi:10.4172/2329-6887.1000106

Page 5 of 5

\begin{tabular}{|c|c|c|c|c|c|c|c|}
\hline \multirow[t]{2}{*}{ No. } & \multirow[t]{2}{*}{ Statement } & \multicolumn{2}{|c|}{ Very important } & \multicolumn{2}{|c|}{ Important } & \multicolumn{2}{|c|}{ Somewhat important } \\
\hline & & Frequencies & $\%$ & Frequencies & $\%$ & Frequencies & $\%$ \\
\hline 1 & $\begin{array}{l}\text { How important is it to include pharmacovigilance -related topics within the B.Pharm } \\
\text { curriculum? }\end{array}$ & 8 & 72.2 & 2 & 18.2 & 1 & 9.1 \\
\hline 2 & $\begin{array}{l}\text { In the future, how important will it be for academic pharmacists/pharmacy lecturers } \\
\text { to know more about pharmacovigilance and Adverse Drug Reactions reporting } \\
\text { process? }\end{array}$ & 4 & 36.4 & 7 & 63.6 & - & - \\
\hline 3 & $\begin{array}{l}\text { In the future, how important will it be for community pharmacists to know about the } \\
\text { basics of pharmacovigilance and Adverse Drug Reactions reporting process? }\end{array}$ & 6 & 54.4 & 5 & 45.5 & - & - \\
\hline 4 & $\begin{array}{l}\text { In the future, how important will it be for hospital pharmacists to know about the } \\
\text { basics of pharmacovigilance and Adverse Drug Reactions reporting process? }\end{array}$ & 7 & 63.6 & 4 & 36.4 & - & - \\
\hline
\end{tabular}

Table 6: The Respondents' Views regarding Teaching of Pharmacovigilance in undergraduate pharmacy programs.

\section{References}

1. Arnold GJ (1998) Clinical recognition of adverse drug reactions: obstacles and opportunities for the nursing profession. J Nurs Care Qual 13: 45-55.

2. Morrison-Griffiths S, Pirmohamed M, Walley T (1998) Reporting of adverse drug reactions: practice in the UK. Nurs Times 94: 52-54.

3. Meyboom R, Olsson S, Thorogood M (2002) Teaching pharmacovigilance. Pharmacovigilance 2: 503-508.

4. MADRAC (2002) Malaysian Adverse Drug Reactions Advisory Committe Bulletin. National Pharmaceutical Control Bureau, $\mathrm{MOH}$, Malaysia.

5. Elkalmi RM, Hassali MA, Ibrahim MIM, Liau SY, Awaisu A (2011) A qualitative study exploring barriers and facilitators for reporting of adverse drug reactions (ADRs) among community pharmacists in Malaysia. J Pharm Health Serv Res 2: $71-78$.

6. Aziz Z, Siang TC, Badarudin NS (2007) Reporting of adverse drug reactions: predictors of under-reporting in Malaysia. Pharmacoepidemiol Drug Saf 16: 223-228.

7. Eland IA, Belton KJ, van Grootheest AC, Meiners AP, Rawlins MD, et al. (1999) Attitudinal survey of voluntary reporting of adverse drug reactions. $\mathrm{Br} \mathrm{J} \mathrm{Clin}$ Pharmacol 48: 623-627.

8. Mariani L (1998) Pharmacovigilance: education and continuing updating. The role of university institutes. Clin Ter 149: 219-225.

9. Sears EL, Generali JA (2005) Adverse drug reaction and medication error reporting by pharmacy students. Ann Pharmacother 9: 452-459.

10. Elkalmi RM, Hassali MA, Ibrahim MI, Widodo RT, Efan QM, et al. (2011) Pharmacy Students' Knowledge and Perceptions About Pharmacovigilance in Malaysian Public Universities. Am J Pharm Educ 75: 96.

11. Birdwell SW, Sullivan DL, Grauer DW, Cable GL (2003) Pharmacy students knowledge of medication-error reporting. Am J Health Syst Pharm 60: 10541055.

12. Oshikoya K, Awobusuyi J (2009) Perceptions of doctors to adverse drug reaction reporting in a teaching hospital in Lagos, Nigeria. BMC Clin Pharmacol 9: 14.

13. Green CF, Mottram DR, Rowe PH, Pirmohamed M (2001) Attitudes and knowledge of hospital pharmacists to adverse drug reaction reporting. $\mathrm{Br} \mathrm{J}$ Clin Pharmacol 51: 81-86

14. Green CF, Mottram DR, Rowe PH, Brown AM (1999) Adverse drug reaction monitoring by United Kingdom hospital pharmacy departments: impact of the introduction of 'yellow card' reporting for pharmacists. Int J Pharm Pract 7: 238246.

15. Sweis D, Wong IK (2000) A survey on factors that could affect adverse drug reaction reporting according to hospital pharmacists in Great Britain. Drug Saf 23: $165-172$

16. Cox AR, Marriott JF, Wilson KA, Ferner R (2004) Adverse drug reaction teaching in UK undergraduate medical and pharmacy programmes. $\mathrm{J}$ Clin Pharm Ther 29: 31-35.

17. Fisher CL, Wilson SA (2010) Pharmacy Students' Exposure to a Culture of Safety and Their Communication of Medication Errors. Am J Pharm Educ 74 $176 a$

18. Mohd Baidi B (2010) Pharmacy curriculum development in Asian and west pacific region. Asian Pacific Pharmacy Education Workshop, Penang- Malaysia.

19. Sing WS (2001) Pharmacy practice in Malaysia. Malaysian Journal of Pharmacy 1: $3-9$

20. Shankar PR, Subish P, Mishra P, Dubey A (2006) Teaching pharmacovigilance to medical students and doctors. Indian J Pharmacol 38: 316-319.

21. Subish P, Izham MIM, Mishra P, Shankar P, Alam K (2010) Education Sessions For Pharmacy Students On Pharmacovigilance: A Preliminary Study. Journal of Clinical and Diagnostic Research 4: 2427-2432.

22. Vallano A, Cereza G, Pedros C, Agusti A, Danés I, et al. (2005) Obstacles and solutions for spontaneous reporting of adverse drug reactions in the hospital. $\mathrm{Br} \mathrm{J}$ Clin Pharmacol 60: 653-658.

23. Nwokeji ED, Rascati KL, Moczygemba LR, Wilson JP (2007) Pharmacoepidemiology education in US colleges and schools of pharmacy. Am J Pharm Educ 71: 80

24. Rascati KL, Conner TM, Draugalis J (1998) Pharmacoeconomic education in US schools of pharmacy. Am J Pharm Educ 62: 167-169.

25. Alldredge BK, Koda-Kimble MA (2006) Count and be counted: preparing future pharmacists to promote a culture of safety. Am J Pharm Educ 70: 92.

26. May $F$ (2007) Teaching and learning pharmacovigilance. Pharmacovigilance, (2ndedn) Wiley Online Library.

27. Hassali MA, Shafie AA, Awaisu A, Ibrahim MIM, Ahmed SI (2009) A public health pharmacy course at a Malaysian pharmacy school. Am J Pharm Educ 73: 136

28. Bhatia A, Kapoor U, Tayal G (2005) A survey of issues regarding ADR and ADR reporting amongst doctors in Delhi. Int J Risk Saf Med 17: 39-46.

29. Biagi C, Montanaro N, Buccellato E, Roberto G, Vaccheri A, et al. (2012) Underreporting in pharmacovigilance: an intervention for Italian GPs (EmiliaRomagna region). Eur J Clin Pharmacol 69: 237-244.

30. Lopez-Gonzalez E, Herdeiro MT, Figueiras A (2009) Determinants of underreporting of adverse drug reactions: a systematic review. Drug Saf 32: 19-31.

31. Kerfoot BP, Conlin PR, Travison T, McMahon GT (2007) Patient safety knowledge and its determinants in medical trainees. J Gen Intern Med 22 1150-1154.

32. Li Q, Zhang SM, Chen H, Fang SF, Yu X, et al. (2004) Awareness and attitudes of healthcare professionals in Wuhan, China to the reporting of adverse drug reactions. Chin Med J (Engl) 117: 856-861.

33. Christensen ST, Søndergaard B, Honoré PH, Bjerrum OJ (2011) Pharmacy student driven detection of adverse drug reactions in the community pharmacy setting. Pharmacoepidemiol Drug Saf 20: 399-404. 